\title{
Prevalence of CTX-M, TEM and SHV Beta-lactamases in Clinical Isolates of Escherichia Coli and Klebsiella Pneumoniae Isolated From Aleppo University Hospitals, Aleppo, Syria
}

\author{
Ibrahim AL-Subol ${ }^{1, *} ;$ Nihad Youssef $^{1}$ \\ ${ }^{1}$ Department of Botany, Faculty of Sciences, University of Aleppo, Aleppo, Syria \\ *Corresponding author: Ibrahim AL-Subol, Department of Botany, Faculty of Sciences, University of Aleppo, Jamea street, Aleppo, Syria. Tel: +96-3212210245, \\ E-mail:alsabalibrahim@gmail.com
}

Received: August 4, 2014; Revised: January 21, 2015; Accepted: February 8, 2015

\begin{abstract}
Background: Extended spectrum $\beta$-lactamases (ESBLs) have emerged as a major threat worldwide, with limited treatment options available.

Objectives: The present study aimed to estimate the prevalence, possible types of ESBL genes and antibiotic resistant patterns of ESBLproducing Escherichia coli (E. coli) and Klebsiella pneumoniae (K. pneumoniae).

Materials and Methods: A total of 199 clinical isolates of E. coli and K. pneumoniae, collected between October 2010 to March 2012, at three University Hospitals in Aleppo city center, in north Syria, were examined phenotypically and genotypically for ESBL production.

Results: The ESBLs were found in (62.89\%) of E. coli and (67.5\%) of K. pneumoniae isolates. The majority of the typeable isolates harbored two or more ESBL genes (73\%). Overall, bla $C$ CX-M-1 was the commonest genotype (81.74\%). Resistances of ESBL isolates to other antibiotics were measured: tremithoprim/sulfamethoxazole (72\%), nalidixic acid (72\%), tetracycline (66\%), gentamicin (54\%) and ciprofloxacin (53\%).

Conclusions: Our study showed high ESBL incidence, with CTX-M genotype as the emerging strain in our hospitals. High co-resistance to other non- $\beta$-lactam antibiotics is a major challenge for the management of ESBL infections.
\end{abstract}

Keywords: Escherichia coli; Klebsiella; beta-Lactamase; Antibiotic Resistance, Bacterial

\section{Background}

Escherichia coli (E. coli) and Klebsiella pneumoniae (K. pneumoniae) strains are opportunistic pathogens and have been associated with various infections, such as urinary tract infections, septicemia, respiratory tract infections, wound infections and diarrhea (1-4). Extendedspectrum $\beta$-lactamases (ESBLs) have emerged worldwide, as a significant cause of community and healthcareassociated infections (5-8). The ESBLs consist of a heterogeneous group of plasmid-mediated bacterial enzymes that confer significant resistance to oxyimino-cephalosporin and monobactam antimicrobials (7, 9-12). The emergence of ESBL-producing bacteria, particularly E. coli and $K$. pneumoniae, is now a critical concern for the development of therapies against bacterial infection (7, 12-15). Various authors have reported the prevalence of ESBLs to be in the range of $6-88 \%$ in various hospitals, especially for K. pneumoniae and E. coli $(6,8,9,16,17)$. The production of $\beta$-lactamases is the most common mechanism responsible for resistance to $\beta$-lactams among clinical isolates of the Enterobacteriaceae family $(4,7,11,13,16,18$, 19). Systemic infections with ESBL producing Enterobacteriaceae are associated with severe adverse clinical outcomes $(9,20,21)$. It is therefore essential for a diagnostic microbiology laboratory to employ updated methods for the detection of ESBL producing strains, taking into account the local epidemiology of ESBL genotypes and their various expression profiles. The ESBL genes are mostly plasmid encoded $(9,11,22)$, and the majority ESBLs can be divided into three genotypes: TEM, SHV, and CTX-M $(12,16$, $17,22,23)$. During the 1990s, ESBL-producing organisms were described mainly as members of the TEM and SHV$\beta$-lactamase families, in E. coli and K. pneumoniae causing nosocomial outbreaks $(6,20,22)$. In the late 1990s, a novel type of ESBL, the CTX-M enzyme, emerged worldwide. The CTX-M types can be divided into five groups, based on their amino acid identities: (CTX-M-1, CTX-M-2, CTX-M-8, CTX-M-9, and CTX-M-25) (14, 17, 20, 24). There are multiple studies have reported the prevalence of ESBLs around the world. However, no information is available on the prevalence and types of ESBLs in Syria.

\section{Objectives}

This study aimed to determine the prevalence of ESBL production among clinical isolates of E. coli and K. pneumoniae and their antibiotic resistant patterns, at the Aleppo University Hospitals. Also, the study investigated the most common ESBL genes, namely: CTX-M, SHV, and TEM, responsible for the ESBL phenomenon among E. coli and $K$. pneumoniae isolates.

Copyright (c) 2015, Infectious Diseases and Tropical Medicine Research Center. This is an open-access article distributed under the terms of the Creative Commons Attribution-NonCommercial 4.0 International License (http://creativecommons.org/licenses/by-nc/4.0/) which permits copy and redistribute the material just in noncommercial usages, provided the original work is properly cited. 


\section{Materials and Methods}

\subsection{Study Location}

This study was performed at three University Hospitals in Aleppo city center, Syria, between October 2010 and March 2012. These are the major teaching hospitals in the northern part of Syria.

\subsection{Bacterial Isolates}

A total of 199 non-duplicate clinical isolates of $E$. coli (159 isolates) and K. pneumoniae (40 isolates) were collected from 199 patients, with different sites of infections. These isolates were identified using traditional bacteriological methods and biochemical testing, with an API 32 E system (bioMerieux SA, Marcy l'Etoile, France) (25), according to the manufacturer's recommendations. The isolates were stored at $-80^{\circ} \mathrm{C}$ in MicroBank cryovials containing 20\% glycerol (Pro-Lab Diagnostics, Round Rock, TX, USA).

\subsection{Antimicrobial Susceptibility Testing}

Antimicrobial susceptibility testing was performed using the disc diffusion method, recommended by the Clinical and Laboratory Standards Institute (CLSI, 2010) (26), with discs from Abtek Biologicals Ltd.(Liverpool, UK). The results were interpreted according to the current guidelines of the (CLSI, 2010) (26). The following antibiotics were tested: Cefotaxime $30 \mu \mathrm{g}$, Ceftazidime $30 \mu \mathrm{g}$, Cefteriaxone $30 \mu \mathrm{g}$, Chloramphenicol $30 \mu \mathrm{g}$, Amoxycillin-clavulanic acid 30/10 $\mu \mathrm{g}$, Piperacillin-tazobactam 100/10 $\mu \mathrm{g}$, Trimethoprim-sulfamethoxazol 1.25/23.75 $\mu \mathrm{g}$, Gentamycin $10 \mu \mathrm{g}$, Tetracycline $30 \mu \mathrm{g}$, Cefepime $30 \mu \mathrm{g}$, Imipenem $10 \mu \mathrm{g}$, Meropenem $10 \mu \mathrm{g}$, Nalidixic acid $30 \mu \mathrm{g}$, Ofloxacin 25 $\mu \mathrm{g}$, Ciprofloxacin $5 \mu \mathrm{g}$ and Amikacin $30 \mu \mathrm{g}$.

\subsection{Detection and Confirmation of ESBL Produc- tion}

E. coli and K. pneumoniae isolates were screened for ESBL production using double disk synergy test (27). The ESBL production was confirmed by the E-test method (27), (bioMerieux, Marcy l'Etoile, France). The K. pneumoniae ATCC 700603 was used as a positive control (presence of bla $_{S H V}$ gene) and E. coli ATCC 25922 was used as a negative control (27), (obtained from American Type Culture Collection, Rockville, MD, USA), for both phenotypic methods and for PCR experiments.

\subsection{Extraction of Plasmids}

Plasmid DNA was isolated from bacterial cells by alkaline lysis method, using the QIAprep Spin Miniprep Kit, which was fully automated on the QIAcube device (Qiagen $\mathrm{GmbH}$, Hilden, Germany), as described by the manufacturer's instructions. The purified plasmid was stored at $-20^{\circ} \mathrm{C}$.

\subsection{Detection of Bla ${ }_{C T X-M}$, Bla $a_{S H V}$, and Bla Genes}

Polymerase chain reaction (PCR) was performed using 5 sets of previously published primers $(28,29)$ to amplify type-specific ESBL genes, including bla $C T X-M-1$, bla $C T X-M-2$, bla $_{C T X-M-9}$, bla $_{T E M}$ and bla $a_{S H V}$. These primers and are listed in Table 1 . The amplified products were analyzed after electrophoresis in $1 \%$ agarose gel at $120 \mathrm{~V}$, for 35 minutes. The gel was visualized by staining with ethidium bromide $(0.5 \mu \mathrm{g} / \mathrm{mL})$ in a dark room. A $100-5000$ bp ladder molecular weight marker (Fermentas, Vilnius, Lithuania) was used. The images of ethidium bromide stained DNA bands were documented using the NiseUV gel documentation system (DAIHAN Scientific, Jijeong-myeon, Wonjusi, Gangwon-do, Korea).

\subsection{Statistical Methods}

We used the statistical program SPSS version 19 (SPSS Inc., Chicago, IL, USA). Differences between proportions were analyzed using Chi-square test $\left(\chi^{2}\right)$. All differences, in which the probability of the null hypothesis was $\mathrm{P} \leq$ 0.05 , were considered significant.

\section{Results}

During the study period, 199 consecutive clinical isolates were isolated. Of these, 159 (80\%) were identified as $E$. coli and 40 (20\%) as K. pneumoniae. Primary antimicrobial susceptibility test showed that the strongest resistance (exceeding 50\%) was to third-generation cephalosporins, nalidixic acid and tremithoprim-sulfamethoxazol, while the majority of these isolates were susceptible to imipenem, meropenem and amikacin. Of 199 isolates, 127 (63.82\%) were ESBL producers. Among the ESBL producers 100/159 (62.89\%) were E. coli and 27/40 (67.5\%) were K. pneumoniae. All ESBL isolates had a minimum inhibitory concentration (MIC) $>16 \mu \mathrm{g} / \mathrm{mL}$ to cefotaxime, more than $96 \%$ had MIC $>2 \mu \mathrm{g} / \mathrm{mL}$ and $43 \%$ of them had MIC $>32 \mu \mathrm{g} /$ $\mathrm{mL}$ to ceftazidime. The ESBL-producing E. coli and K. pneumoniae isolates had a significantly higher resistance to other groups of antibiotics beyond beta-lactams (Table 2 ).

The phenotypically identified ESBL-producing E. coli and K. pneumoniae were subjected to PCR using bla CTX$M-1$, bla $a_{T E M}$, bla $a_{S H V}$, bla $a_{C T X-M-g^{a n d}} b_{C T X-M-2}$ specific primers. Of the 98 phenotypically ESBL-producing E. coli isolates (there were two isolates that died during frozen storing), 88/98 (89.80\%) were positive for ESBL genes and $10 / 98$ isolates (10.20\%) were negative. For phenotypically ESBL-producing K. pneumoniae, all isolates 27 (100\%) were positive for ESBL genes. The detected bla $a_{C T X-M-1}, b l a_{T E M}$, bla $_{S H V}$ and bla $C$ CTX-M-ggenes were present alone or in combination with each other. The CTX-M-1 type was the most prevalent among both E. coli and K. pneumoniae isolates, followed by the SHV and TEM types, respectively, while bla CTX-M-2 type were not detected (Table 3 ). The results of PCR-products electrophoresis showed genomic 
AL-Subol I et al.

patterns related to $b l a_{C T X-M-1}(780 \mathrm{bp}), b_{S H V}(1007 \mathrm{bp})$, bla $_{\text {TEM }}$ (971 bp) and bla CTX-M-9 (857 bp), (Figure 1 - 3). Seventy three percent of the isolates had two or more ESBL genes. All ESBL K. pneumoniae tested had at least two ESBL genes, while 57 tested isolates (65\%) of E. coli had at least two ESBL genes, (Tables 4 and 5).

Table 1. Oligonucleotide Sequences of Primers Used in This Study

\begin{tabular}{lccc}
\hline $\begin{array}{l}\text { Primer } \\
\text { Name }\end{array}$ & Primer Sequence $\left(\mathbf{5}^{\prime} \mathbf{- 3}^{\prime}\right)$ & $\begin{array}{c}\text { Amplicon } \\
\text { Size, bp }\end{array}$ & Ref \\
\hline CTX-M-1 & & 780 & $(28)$ \\
Forward & CGT CAC GCT GTT GTT AGG AA & & \\
\hline Reverse & ACG GCT TT CTG CCT TAG GTT & & \\
CTX-M-2 & & 901 & $(28)$ \\
Forward & TTA ATG ATG ACT CAG AGC ATTC & & \\
Reverse & GAT ACC TCG CTC CATTTA TTG & & \\
\hline CTX-M-9 & & 857 & $(29)$ \\
Forward & GTG ACA AAG AGA GTG CAA CGG & & \\
\hline Reverse & ATG ATT CTC GCC GCT GAA GCC & & \\
\hline TEM & & 971 & $(28)$ \\
Forward & TCG GGG AAA TGT GCG & & \\
Reverse & TGC TTA ATC AGT GAG GCA CC & & \\
\hline SHV & & 1007 & $(28)$ \\
\hline Forward & GCC GGG TTA TTC TTA TTT GTC GC & & \\
\hline Reverse & ATG CCG CCG CCA GTC A & & \\
\hline
\end{tabular}

Table 2. Differences of Resistance Rates Between Extended Spectrum $\beta$-lactamases and Non-Extended Spectrum $\beta$-lactamases Producing Isolates Against some antibiotics ${ }^{\mathrm{a}, \mathrm{b}}$

\begin{tabular}{lccc}
\hline Antibiotics & $\begin{array}{c}\text { ESBL } \\
(\mathbf{n = 1 2 7})\end{array}$ & $\begin{array}{c}\text { Non ESBL } \\
(\mathbf{n}=\mathbf{7 2})\end{array}$ & PValue \\
\hline Gentamycin & $69(54.33)$ & $5(6.94)$ & $<0.0001$ \\
Tetracycline & $84(66.14)$ & $27(37.5)$ & $<0.0001$ \\
Nalidixic Acid & $92(72.44)$ & $25(34.72)$ & $<0.0001$ \\
Ciprofloxacin & $67(52.76)$ & $8(11.11)$ & $<0.0001$ \\
Tremithoprim-Sulfamethox- & $92(72.44)$ & $34(47.22)$ & $<0.0001$ \\
azol & & & \\
\hline a Data are presented No.(\%), n= number of isolates. & & \\
b Abbreviation: ESBL, extended spectrum $\beta-l a c t a m a s e s$.
\end{tabular}

Table 3. Distribution of Extended Spectrum $\beta$-lactamases Genotypes Detected Among Bacterial Species ${ }^{\mathrm{a}}$

\begin{tabular}{lccc}
\hline $\begin{array}{l}\text { Genotype of } \\
\text { Enzymes }\end{array}$ & \multicolumn{3}{c}{ Bacterial Species } \\
\cline { 2 - 4 } & $\begin{array}{l}\text { K.pneumoni- } \\
\text { ae }(\mathbf{n}=\mathbf{2 7})\end{array}$ & & \\
\hline CTX-M-1 & $27(100)$ & $67(76.14)$ & $94(81.74)$ \\
SHV & $25(92.59)$ & $51(57.95)$ & $76(66.09)$ \\
TEM & $16(59.59)$ & $30(34.09)$ & $46(40)$ \\
CTX-M-9 & $0(0)$ & $5(5.68)$ & $5(4.35)$ \\
CTX-M-2 & $0(0)$ & $0(0)$ & $0(0)$ \\
\hline
\end{tabular}

\footnotetext{
${ }^{\mathrm{a}}$ Data are presented as No.(\%), $\mathrm{n}=$ number of isolates.
}

Table 4. Combinations of Three or Two of ESBL Genes Detected in Extended Spectrum $\beta$-lactamases-producing Klebsiella pneumoniae Isolates ${ }^{\text {a }}$

\begin{tabular}{lc}
\hline Genotypes & K. pneumoniae $(\mathbf{n}=\mathbf{2 7})$ \\
\hline CTX-M-1 + SHV + TEM & $14(51.85)$ \\
CTX-M-1 + SHV & $11(40.74)$ \\
CTX-M1 + TEM & $2(7.41)$ \\
Total & $27(100)$ \\
\hline
\end{tabular}

$\mathrm{a}$ Data are presented as No.(\%), $\mathrm{n}=$ number of isolates.

Table 5. Genotypes and Combinations of Three or Two of ESBL Genes Detected in Extended Spectrum $\beta$-lactamases-producing Escherichia coli Isolates ${ }^{\text {a }}$

\begin{tabular}{lc}
\hline Genotypes & E. coli $(\mathbf{n}=\mathbf{8 8})$ \\
\hline Two or Three Combination Genes & \\
CTX-M-1 + SHV & $27(30.68)$ \\
CTX-M-1 + TEM & $17(19.32)$ \\
CTX-M-1 + SHV + TEM & $8(9.09)$ \\
\hline SHV + CTX-M-9 & $3(3.41)$ \\
SHV + TEM & $2(2.27)$ \\
Total & $57(64.78)$ \\
One Genotype & \\
\hline CTX-M-1 & $15(17.05)$ \\
SHV & $11(12.5)$ \\
TEM & $3(3.41)$ \\
CTX-M-9 & $2(2.27)$ \\
\hline Total & $31(35.22)$ \\
\hline
\end{tabular}

a Data are presented as No.(\%), $\mathrm{N}=$ number of isolates.

Figure 1. Gel Electrophoresis of the PCR Products of $b l a_{C T X-M-1}$ Gene

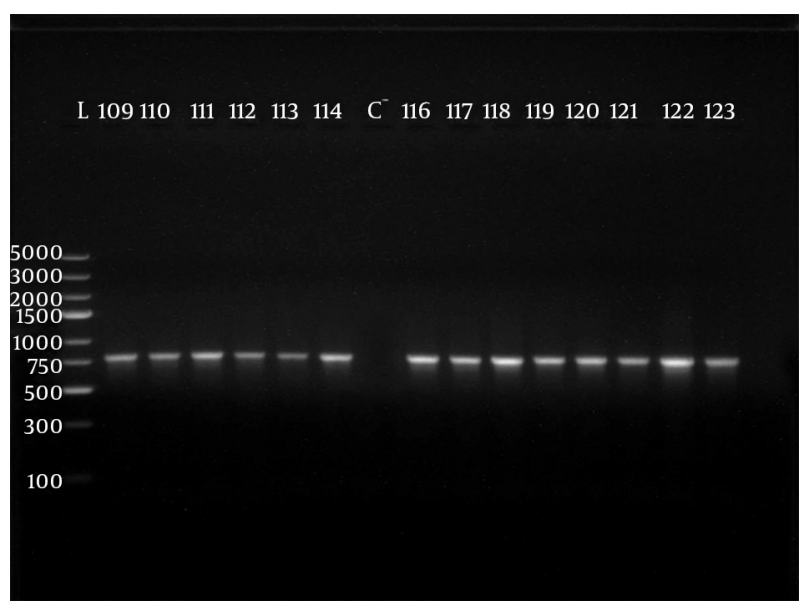

L lane, molecular weight marker; Gene Ruler 100 - 5000 bp DNA ladder, lanes numbered 109, 110, 111, 112, 113, 114,116, 117, 118, 119, 120, 121, 122 and 123 show (780 bp) bands of PCR products while lane $\mathrm{C}^{-}$shows negative control. 
Figure 2. Gel Electrophoresis of the PCR Products of bla ${ }_{S H V}$ Gene

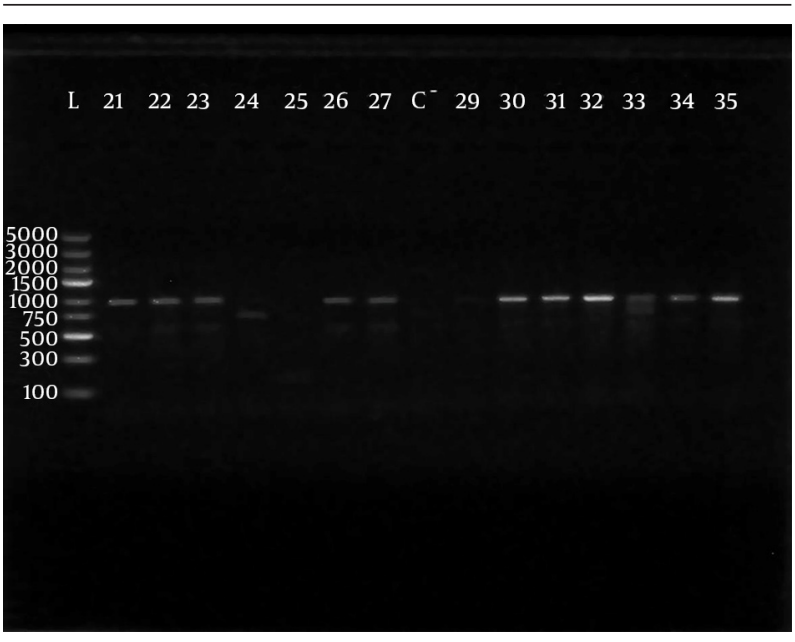

L lane, molecular weight marker; Gene Ruler 100 - 5000 bp DNA ladder lanes numbered 16,17, 18, 19, 20, 21, 23, 24 and 25 show (1007 bp) bands of PCR products, lanes numberd 26, 28, 29 show negative results, while lanes $\mathrm{C}^{+}$and $\mathrm{C}^{-}$show positive and negative controls respectively.

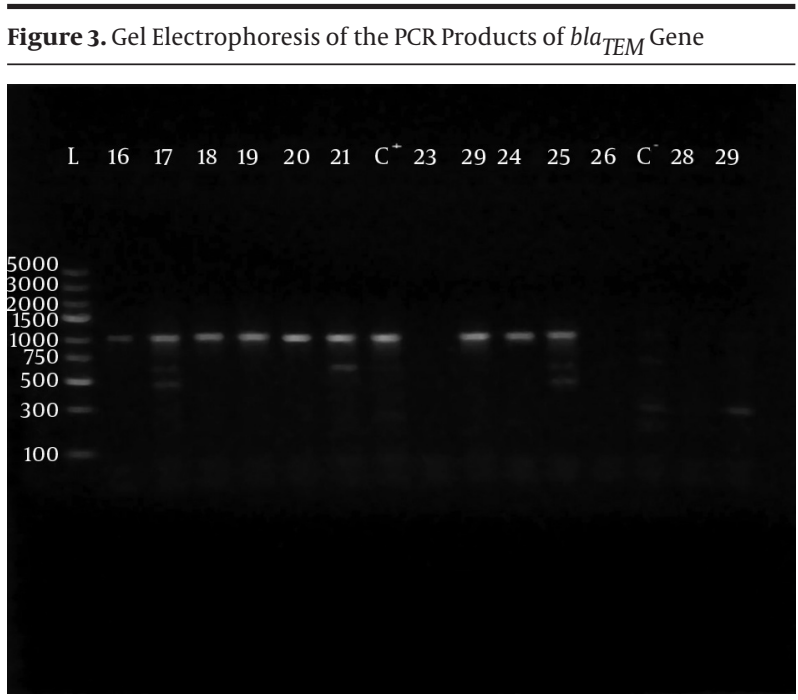

L lane, molecular weight marker; Gene Ruler 100 - 5000 bp DNA ladder, lanes numbered 21, 22, 23, 26, 27, 30, 31, 32, 33, 34 and 35 show (971 bp) bands of PCR products, lanes numbered 24,25 and 29 show negative results, while lane $\mathrm{C}^{-}$shows negative control.

\section{Discussion}

Knowledge on local antimicrobial resistance trends among clinical isolates is important for evidence based recommendations in the empirical antibiotic treatment of infections. The current study described the antimicrobial resistance rates including detection of ESBL among E. coli and K. pneumoniae isolates, which are the predominant ESBL producers. In the current study, the antimicrobial resistance rates of both E. coli and K. pneumoniae isolates was high to first line antimicrobial agents, such as cotrimoxazole, amoxicillin/clavulanic acid, nalidixic acid, ceftriaxone and ciprofloxacin. Our result is consistent with multiple studies $(8,14,18,24,30-33)$. The observation may be due to the wide use of these drugs empirically, because they are relatively cheap and also, by being oral antibiotics, they are easy to administer. In the present study, the carbapenems (imipenem and meropenem) and amikacin were very active antimicrobial agents against the ESBL and non-ESBL-producing E. coli and K. pneumoniae isolates. This is in agreement with other studies $(3,9,10,13$, $18,23,31)$. During the past decade, ESBL producing Gramnegative bacilli, especially E. coli and K. pneumonia have emerged as serious pathogens, both in hospital and community acquired infections, worldwide. The occurrence of ESBL among clinical isolates greatly varies worldwide and geographically, and is rapidly changing over time (14, $24,33)$. In the present study, ESBL phenotypes were found to be positive in 127 isolates (63.82\%). We demonstrated a high prevalence of ESBL production by E. coli $(62.89 \%)$ and K. pneumoniae (67.5\%) isolates, at Aleppo Univesity Hospitals, Aleppo, Siria. Similar results were reported in Jordan (10) (50.8\%), Sudan (11) (59.6\%), Iran (34) (59.2\%), India (17) (63.6\%) of E. coli and (66.7\%) of K. pneumoniae and in Turkey (35), (39.4\%) of E. coli and (60.6\%) of K. pneumoniae. However, our result is higher compared to other reports from Germany (36) (1.6\%) of enterobacteriaceae, Switzerland (20) (0.7\%) of enterobacteriaceae and Saudia Arabia (6), where (20.4\%) of E. coli were ESBL-producing. On the other hand, other studies in China, Nigeria and India reported high percentages of ESBL-producing isolates, with $94.1 \%$ E. coli (4) and (52.4\%) K. pneumoniae, in Nigerria (12), (80\%) of E. coli and K. pneumoniae and in India (77\%) of E. coli and K. pneumoniae were ESBL-producing (37). The high prevalence of ESBL-producing isolates described in this study was probably due to the large amount of thirdgeneration cephalosporins consumed by patients.

Compared with ESBL-negative isolates, ESBL-positive E. coli and K. pneumoniae isolates showed a significantly high rate of resistance to non- $\beta$-lactam antibiotics, such as cotrimoxazole, nalidixic acid, tetracycline, gentamycin and ciprofloxacin. This association between ESBL production and decreased susceptibility to non- $\beta$-lactams is in line with the findings of previous investigations, (8, $14,20,24,32)$. This is probably because the ESBL genes are located on a plasmid that can be transferred from one organism to another, rather easily, and can incorporate genetic material coding for resistance to other antimicrobial classes. Our results demonstrated that all ESBL isolates had MIC $>16 \mu \mathrm{g} / \mathrm{mL}$ to cefotaxime and more than $90 \%$ had MIC $>2 \mu \mathrm{g} / \mathrm{mL}$ to ceftazidime and $43 \%$ had MIC > $32 \mu \mathrm{g} / \mathrm{mL}$ to ceftazidime. Similar results were reported in various studies $(19,31,32)$.

In the present study, genotypic survey on 125 confirmed ESBL phenotype strains (there were two isolates that died during frozen store) by PCR revealed that115 isolates (92\%) were positive genotypes for at least one of the studied genes. The negative amplification in the remaining isolates may be due to the presence of uncommon of other 
ESBL genes, which we did not explore further. Of all phenotypically identified ESBL-producing K. pneumonia, 27 isolates $(100 \%)$ were positive genotypes, compared with 88 isolates of E. coli, $89.80 \%$ were positive. The PCR results showed that among ESBL gene families, bla CTX-M-1 was the most prevalent in both K. pneumoniae and E. coli ESBLproducing isolates, $100 \%$ and $76.14 \%$, respectively. A very high prevalence of $b a_{S H V}(92.59 \%)$ and (57.95\%) was also detected among $K$. pneumoniae and $E$. coli isolates, respectively. These results are in agreement with other studies, such as in Saudia Arabia (6), which reported that, 96.8\% of CTX-M types in, E. coli belonged to CTX-M-1 group and 3.23\% belonged to CTX-M-9 group; the study in Sudan (11) showed that CTX-M gene was found in $71.4 \%$ of E. coli and $86.4 \%$ of K. pneumonia and in Switzerland (20), mentioned that CTX-M genes were the most prevalent and most of them belong to the CTX-M-1 group. However, the Brazilian study found that the highest prevalence ESBL genes were aTEM followed by CTX-M type.

In conclusion, the results of this study suggest the importance of ESBL-producing E. coli and K. pneumoniae, as a cause of infections in the Aleppo University Hospitals, Aleppo, Siria. The high prevalence of multidrug-resistant organisms should be taken into account when choosing therapeutic agents, while the continuous local monitoring of resistance patterns is necessary to adequately select an empirical antimicrobial therapy. Further studies, aimed at unraveling the molecular mechanisms of resistance, will provide a better understanding of the epidemiology associated with ESBL-producing species of Enterobacteriaceae.

\section{Acknowledgements}

This study is a major research project assigned and funded by the University of Aleppo, Aleppo, Syria. We are also thankful to Dr. Shaker AL-Faris for his supporting and improve the idea of this work.

\section{Financial Disclosure}

There are no relevant financial 16.03.2015 interests in this manuscript. We certify that all financial and material support for this research and work are clearly acknowledged in the manuscript. We certify that all my affiliations with or financial and/or material support from any organization that may either gain or lose financially from the results or conclusions of this study are disclosed completely hereunder.

\section{References}

1. Toroglu S, Keskin D. Antimicrobial Resistance and Sensitivity among Isolates of Klebsiella pneumoniae from Hospital Patients in Turkey. Int. J Agric Biol. 2011;13(1):941-6.

2. Kim MH, Lee HJ, Park KS, Suh JT. Molecular characteristics of extended spectrum beta-lactamases in Escherichia coli and Klebsiella pneumoniae and the prevalence of qnr in Extended spectrum beta-lactamase isolates in a tertiary care hospital in Korea. Yonsei Med J. 2010;51(5):768-74.

3. Lim KT, Yeo CC, Yasin RM, Balan G, Thong KL. Characterization of multidrug-resistant and extended-spectrum beta-lactamaseproducing Klebsiella pneumoniae strains from Malaysian hospitals. J Med Microbiol. 2009;58(Pt 11):1463-9.

4. Wang XR, Chen JC, Kang Y, Jiang N, An SC, Gao ZC. Prevalence and characterization of plasmid-mediated blaESBL with their genetic environment in Escherichia coli and Klebsiella pneumoniae in patients with pneumonia. Chin MedJ (Engl). 2012;125(5):894-900.

5. Nakamura T, Komatsu M, Yamasaki K, Fukuda S, Miyamoto Y, Higuchi T, et al. Epidemiology of Escherichia coli, Klebsiella species, and Proteus mirabilis strains producing extended-spectrum beta-lactamases from clinical samples in the Kinki Region of Japan. Am J Clin Pathol. 2012;137(4):620-6.

6. Al-Agamy MH, Shibl AM, Hafez MM, Al-Ahdal MN, Memish ZA Khubnani H. Molecular characteristics of extended-spectrum beta-lactamase-producing Escherichia coli in Riyadh: emergence of CTX-M-15-producing E. coli ST131. Ann Clin Microbiol Antimicrob. 2014;13:4.

7. Shanthi M, Sekar U. Extended spectrum beta lactamase producing Escherichia coli and Klebsiella pneumoniae: risk factors for infection and impact of resistance on outcomes. J Assoc Physicians India. 2010;58 Suppl:41-4.

8. Tonkic M, Goic-Barisic I, Punda-Polic V. Prevalence and antimicrobial resistance of extended-spectrum beta-lactamasesproducing Escherichia coli and Klebsiella pneumoniae strains isolated in a university hospital in Split, Croatia. Int Microbiol. 2005;8(2):119-24.

9. Ahmed OI, El-Hady SA, Ahmed TM, Ahmed IZ. Detection of bla SHV and bla CTX-M genes in ESBL producing Klebsiella pneumoniae isolated from Egyptian patients with suspected nosocomial infections. Egypt J Med Hum Gene. 2013;14(3):277-83.

10. Batarseh A, Soneah S, Mardeni R, Elmadni K, Noor M, Ashour NA antibiotic resistance patterns of multidrug resistant and extended-spectrum $\beta$-lactamase producing Esherichia coli urinary isolates at queen Rania al-abdullah hospital for children. Jordan $Z U$ M J. 2013;19(5):286-93.

11. Ahmed OB, Omar AO, Asghar AH, Elhassan MM. Prevalence of TEM, SHV and CTX-M genes in Escherichia coli and Klebsiella spp. Urinary Isolates from Sudan with confirmed ESBL phenotype. Life Sci. 2013;10(2):191-5

12. Alo MN, Anyim C, Igwe JC, Elom M. Presence of extended spectrum $\beta$-lactamase (ESBL) E. coli and K. pneumonia isolated from blood cultures of hospitalized patients. Adv Appl Sci Res. 2012;3(2):821-5.

13. Asghar AH. prevalence and potential types of extended spectrum $\beta$-lactamase among Escherishia coli and Klebsiella species in Makkah hospitals. Oxford Res forum J. 2007;2(4):47-55.

14. Pitout JD, Gregson DB, Campbell L, Laupland KB. Molecular characteristics of extended-spectrum-beta-lactamase-producing Escherichia coli isolates causing bacteremia in the Calgary Health Region from 2000 to 2007: emergence of clone ST131 as a cause of community-acquired infections. Antimicrob Agents Chemother. 2009;53(7):2846-51.

15. Yan JJ, Hsueh PR, Lu JJ, Chang FY, Shyr JM, Wan JH, et al. Extended-spectrum beta-lactamases and plasmid-mediated AmpC enzymes among clinical isolates of Escherichia coli and Klebsiella pneumoniae from seven medical centers in Taiwan. Antimicrob Agents Chemother. 2006;50(5):1861-4.

16. Wollheim C, Guerra IM, Conte VD, Hoffman SP, Schreiner FJ Delamare AP, et al. Nosocomial and community infections due to class A extended-spectrum beta-lactamase (ESBLA)-producing Escherichia coli and Klebsiella spp. in southern Brazil. Braz J Infect Dis. 2011;15(2):138-43.

17. Goyal A, Prasad KN, Prasad A, Gupta S, Ghoshal U, Ayyagari A Extended spectrum beta-lactamases in Escherichia coli \& Klebsiella pneumoniae \& associated risk factors. Indian J Med Res. 2009;129(6):695-700.

18. Mugnaioli C, Luzzaro F, De Luca F, Brigante G, Perilli M, Amicosante G, et al. CTX-M-type extended-spectrum beta-lactamases in Italy: molecular epidemiology of an emerging countrywide problem. Antimicrob Agents Chemother. 2006;50(8):2700-6.

19. Rao SP, Rama PS, Gurushanthappa V, Manipura R, Srinivasan K. Extended-Spectrum Beta-Lactamases Producing Escherichia coli and Klebsiella pneumoniae: A Multi-Centric Study Across Karna- 
taka. J Lab Physicians. 2014;6(1):7-13.

20. Lartigue MF, Zinsius C, Wenger A, Bille J, Poirel L, Nordmann P. Extended-spectrum beta-lactamases of the CTX-M type now in Switzerland. Antimicrob Agents Chemother. 2007;51(8):2855-60.

21. Khan E, Schneiders T, Zafar A, Aziz E, Parekh A, Hasan R. Emergence of CTX-M Group 1-ESBL producing Klebsiella pneumonia from a tertiary care centre in Karachi, Pakistan.J Infect Dev Ctries. 2010;4(8):472-6.

22. Barguigua A, El Otmani F, Talmi M, Bourjilat F, Haouzane F, Zerouali K, et al. Characterization of extended-spectrum beta-lactamase-producing Escherichia coli and Klebsiella pneumoniae isolates from the community in Morocco. JMed Microbiol. 2011;60(Pt 9):1344-52.

23. Okesola AO, Oni AA. Prevalence of extended-spectrum $\beta$-lactamase producing Klebsiella in a tertiary care hospital in South West Nigeria. Int J Pharm Biomed Sci. 2012;3(4):148-51.

24. Brinas L, Lantero M, de Diego I, Alvarez M, Zarazaga M, Torres C. Mechanisms of resistance to expanded-spectrum cephalosporins in Escherichia coli isolates recovered in a Spanish hospital.J Antimicrob Chemother. 2005;56(6):1107-10.

25. Wei TY, Charles W. Advanced Techniques in Diagnostic Microbiology.USA: springer; 2006.

26. Clinical and Laboratory Standards Institute.. Performance Stan dards for Antimicrobial Susceptibility Testing; Twenty-Second Informational Supplement .Pennsylvania: Wayne press; 2010.

27. Paterson DL, Bonomo RA. Extended-spectrum beta-lactamases: a clinical update. Clin Microbiol Rev. 2005;18(4):657-86

28. Hussain M, Hasan F, Shah AA, Hameed A, Jung M, Rayamajhi N, et al. Prevalence of class A and AmpC beta-lactamases in clinical Escherichia coli isolates from Pakistan Institute of Medical Science, Islamabad, Pakistan. Jpn J Infect Dis. 2011;64(3):249-52.

29. Coque TM, Oliver A, Perez-Diaz JC, Baquero F, Canton R. Genes encoding TEM-4, SHV-2, and CTX-M-10 extended-spectrum beta-lactamases are carried by multiple Klebsiella pneumoniae clones in a single hospital (Madrid, 1989 to 2000). Antimicrob Agents Chemother. 2002;46(2):500-10

30. Moyo SJ, Aboud S, Kasubi M, Lyamuya EF, Maselle SY. Antimicrobial resistance among producers and non-producers of extended spectrum beta-lactamases in urinary isolates at a tertiary Hospital in Tanzania. BMC Res Notes. 2010;3:348.

31. Alfaresi MS, Elkoush AA. Real-time polymerase chain reaction for rapid detection of genes encoding SHV extended-spectrum betalactamases. Indian J Med Microbiol. 2010;28(4):332-6.

32. Nasehi L, Shahcheraghi F, Nikbin VS, Nematzadeh S. PER, CTX $\mathrm{M}$, TEM and SHV Beta-lactamases in Clinical Isolates of Klebsiella pneumoniae Isolated from Tehran, Iran. Iran J Basic Med Sci. 2010;13(3):111-8.

33. Tofteland S, Haldorsen B, Dahl KH, Simonsen GS, Steinbakk M Walsh TR, et al. Effects of phenotype and genotype on methods for detection of extended-spectrum-beta-lactamase-producing clinical isolates of Escherichia coli and Klebsiella pneumoniae in Norway. J Clin Microbiol. 2007;45(1):199-205.

34. Ghafourian S, Bin Sekawi Z, Sadeghifard N, Mohebi R, Kumar Neela V, Maleki A, et al. The Prevalence of ESBLs Producing Klebsiella pneumoniae Isolates in Some Major Hospitals, Iran. Open Microbiol J. 2011;5:91-5.

35. Serefhanoglu K, Turan H, Timurkaynak FE, Arslan H. Bloodstream infections caused by ESBL-producing E. coli and K. pneumoniae: risk factors for multidrug-resistance. Braz J Infect Dis 2009;13(6):403-7.

36. Grobner S, Linke D, Schutz W, Fladerer C, Madlung J, Autenrieth IB, et al. Emergence of carbapenem-non-susceptible extendedspectrum beta-lactamase-producing Klebsiella pneumoniae isolates at the university hospital of Tubingen, Germany. J Med Microbiol. 2009;58(Pt 7):912-22.

37. Roy S, Mukherjee S, Singh AK, Basu S. CTX-M-9 group extendedspectrum beta-lactamases in neonatal stool isolates: emergence in India. Indian J Med Microbiol. 2011;29(3):305-8. 